\title{
Modified Bone Density Fractionation Method for Palaeodietary Studies
}

\author{
Ji Young Shin \\ Conservation Science Division, National Research Institute of Cultural Heritage, 82 Munji-ro, Yuseong-gu, \\ Daejeon 305-380, Korea.E-mail: archsci@korea.kr \\ Received August 3, 2010, Accepted October 22, 2010

\begin{abstract}
The bone density fractionation method is a potential palaeodietary tool in tracing lifetime dietary changes as well as separating diagenetically altered fractions. This paper presents a workable bone density fractionation method that uses a devised mathematical model and the particle size distribution. Different grinding methods, i.e., a Spex $\mathrm{LN}_{2}$ mill, a Disc mill and a Micronising mill, were used to reduce archaeological bone particles to an appropriate size range, which was then analyzed by a Laser particle sizer. It was found that density profiles are in good agreement with the diagenetic parameters, and with their stable isotope results.
\end{abstract}

Key Words: Bone density fractionation, Bone diagenesis, Particle size, Palaeodiet, Stable isotope analysis

\section{Introduction}

Palaeodietary research based on a stable isotope analysis of the inorganic and organic phase in archaeological bone relies on the assumption that the isotopic values reflect in vivo signals. ${ }^{1,2}$ Over the past three decades, much attention has been focused on stable isotope analysis to reconstruct the palaeodiet such as diet changes attributed to agricultural revolution, sex and social status. ${ }^{3,4}$ The underlying assumption of stable isotope analysis is that the isotopic composition of bone tissue is expected to be a direct and constant function of diet, where the stable isotope ratios should not decay or change in abundance through time. Stable isotope ratios are expressed in the $\delta$ notation, in parts per thousand (per mil or \%o) relative to an international standard. The $\delta^{13} \mathrm{C}$ value (\%) that expresses the ratio of ${ }^{13} \mathrm{C}$ to ${ }^{12} \mathrm{C}$ in a sample is compared to the ratio in the VPDB standard according to the following equation:

$$
\delta^{13} \mathrm{C}=\left[\left[\left({ }^{13} \mathrm{C} /{ }^{12} \mathrm{C}\right)_{\text {sample }} /\left({ }^{13} \mathrm{C} /{ }^{12} \mathrm{C}\right)_{\mathrm{VPDB}}\right]-1\right] \times 1000
$$

The value $\delta^{15} \mathrm{~N}(\%)$ that expresses the ratio of ${ }^{15} \mathrm{~N}$ to ${ }^{14} \mathrm{~N}$ in a sample is compared to the ratio in the AIR standard according to the following equation:

$$
\delta^{15} \mathrm{~N}=\left[\left[\left({ }^{15} \mathrm{~N} /{ }^{14} \mathrm{~N}\right) \text { sample } /\left({ }^{15} \mathrm{~N} /{ }^{14} \mathrm{~N}\right) \text { AIR }\right]-1\right] \times 1000
$$

However, postmortem alteration in archaeological bone may alter the biogenic signatures as a result of the geochemical conditions of its burial environment. ${ }^{5,6,7}$

Although diagenesis is an inevitable process in archaeological bone, bone density can potentially recover lifetime signatures when reconstructing a palaeodietary history by separating the biogenic and diagenetic signals using fractionation. In addition, we can select a stage of life and trace changes in diet and/ or residence. Herman and Richelle ${ }^{8}$ first introduced the density fractionation method, which is a well-established method in mineral analysis, to modern bone and dental tissues with respect to age, nutrition and disease using mixtures of toluene and bromoform. Bell et al. ${ }^{9}$ drew the idea of fractionating bone density from a contemporary biomedical research tool to archaeological bone. ${ }^{10}$ They applied this method to bones, which are known to undergo significant diet change during their lifetime.

According to the stable isotopic analysis of each density fraction, they maintained that changes in $\delta^{13} \mathrm{C}$ values imply a change in an individual's diet from a $\mathrm{C}_{4}$-based diet to $\mathrm{a}_{3}$-based diet shortly before death. They explained that a less well-mineralized fraction reflects younger (more recently formed) bone, whereas a highly-mineralized fraction represents relatively older bones. Shin et al. ${ }^{11}$ demonstrated that density fractionated bone tissues within an individual could track the rise in atmospheric radiocarbon due to nuclear bomb testing.

In the field of bone density fractionation, there have been few systematic approaches related to archaeological bone. In order to apply the bone density fractionation method to palaeodietary research, two main factors should be assured: the factors influencing density differences and those related to obtaining reliable particle size.

First, differences in bone density may occur for two main reasons, i.e., bone maturation caused by metabolism in vivo,12 and exogenous mineralization caused by microbacterial attack after burial. ${ }^{13,14}$ The increase in bone density in vivo is closely related to bone formation and maturation, during the continuous remodelling of bone that occurs throughout life. The precipitation of mineral salts is highly relevant to this event, rather than collagen, as it displaces interstitial water. In this case, lower density implies the younger bone minerals in normal physiological conditions. After death, the bone density increases due to the changes in the mean atomic number profiles that are caused by diagenetic processes. ${ }^{5,13}$

Second, the significance of the "liberation size" prior to density fractionation has been argued by many researchers. ${ }^{9,15,16}$ If the particle size is larger than a certain range, the particles can exist with two or more density ranges. However, these researchers did not define the proper size range; moreover, they only reported their mean values as analyzed by SEM. Using the SEM and mean values may be limited due to the difficulties in finding the representative area and the possibility of the presence of large particles. 
In this paper, I devised a modified mathematical model to ensure the proper particle size to obtain the "liberation size". I also discuss the appropriate grinding method to obtain this size, which shows an improvement over the results of previous study. ${ }^{11}$

After obtaining the proper particle size, bone density fractionation is carried out, and the density profiles are compared with their diagenetic state based on a histological index. Finally, each density profile is compared to the stable isotope results, which can also be used as a palaeodietary tool. If we can separate bone density fractions which are influenced by biogenic and diagenetic factors, it will make the chemical values used in 'in vivo' palaeodietary reconstruction, where normally the stable isotopic value reflects the mixing signal of these biogenic and diagenetic fractions, more reliable. If a difference exists in the isotopic values between the biogenic fraction and the diagenetically altered fraction, the separation and use of only the biogenic fraction will increase the level of confidence in palaeodietary research. On the other hand, if there is little or no difference between these values, masking or misinterpretation of in vivo signatures by the diagenetic fraction is not a concern. In addition, it will be worthwhile to determine the relationship between the diagenetic state and density profiles.

\section{Experimental Section}

Materials. Archaeological human bone samples, specially the femoral shaft, were taken from 2 sites, provided by Oxfordshire Museums Service. The first sets of human bones were from the Greyfriars site, where there was a domestic occupation in the Late Saxon and Medieval periods. These are termed GF1, GF2 and GF3. The second set of human bones was from the Repton Middle Saxon cemeteries, where archaeological investigations have identified the existence of wintersetl (winter settlement) of Vikings in 873-4 AD. Three bones were selected: they are termed here as RT1, RT2 and RT3.

Mathematical Model for the liberation Size. As noted above, it is important to define a reliable particle size range and an

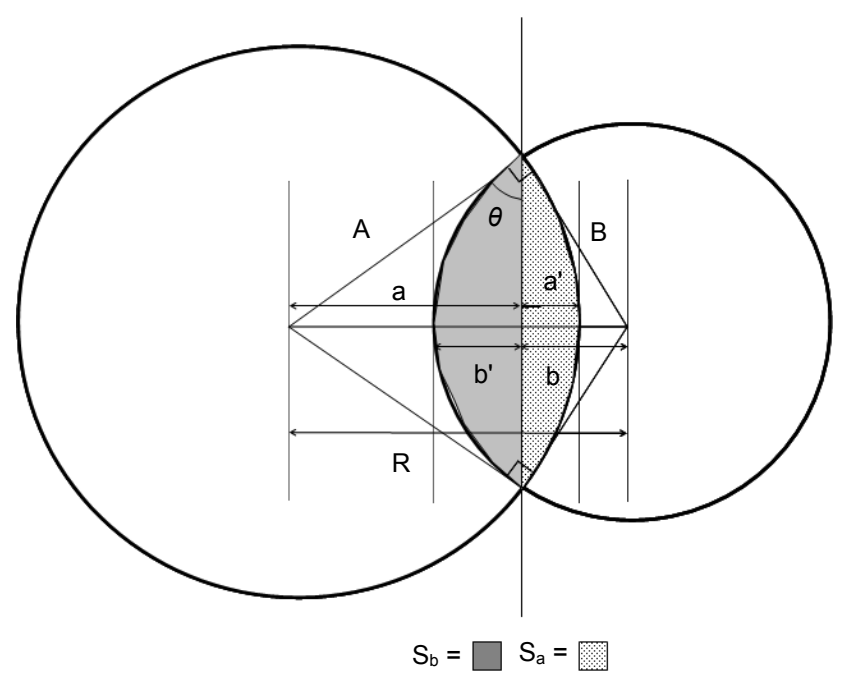

Figure 1. Mathematical model for liberation size. appropriate method of preparation because bone is remodeled at the osteonal level and because the density fractionation method should be carried out on particles that are small relative to the size of an osteon. We assume ' $A$ ' as a particle, which is composed of a uniform density, whereas ' $\mathrm{B}$ ' is the actual sampled particle in grinding process. If we select the sampled particle ' $B$ ' within the particle ' $A$ ', then we can call it as a pure $A$ in a common sense. Here we propose a simple mathematical model to verify the probability to obtain pure sampled particle, that is liberation particle size, by calculation of overlapping area $(\mathrm{S}=$ $\mathrm{S}_{\mathrm{a}}+\mathrm{S}_{\mathrm{b}}$ ), see Figures 1 and 2 .

$$
\mathrm{A}=\mathrm{a}+\mathrm{a}^{\prime}, \mathrm{B}=\mathrm{b}+\mathrm{b}^{\prime}, \mathrm{R}=\mathrm{a}+\mathrm{b}
$$

$(\mathrm{A}=$ radius of large circle, $\mathrm{B}=$ radius of small circle $)$

$$
\mathrm{A}^{2}-\mathrm{a}^{2}=\mathrm{B}^{2}-\mathrm{b}^{2}=\mathrm{B}^{2}-(\mathrm{R}-\mathrm{a})^{2}
$$

(according to the Pythagorean theorem)

Therefore, $a=\frac{A^{2}-B^{2}+R^{2}}{2 R} b=\frac{R^{2}-A^{2}+B^{2}}{2 R}$

$$
x=A \sin \theta, d x=A \cos \theta d \theta
$$

Area $(\mathrm{S})$ reflects the overlapping area of two circles, $\mathrm{S}=\mathrm{S}_{\mathrm{a}}+$ $\mathrm{S}$.

$$
\begin{aligned}
\operatorname{Area}\left(S_{a}\right) & =2 \int_{x=a}^{x=A} \sqrt{A^{2}-x^{2}} d x=2 \int_{x=a}^{x=A} A^{2} \cos ^{2} \theta d \theta \\
& =\left.A^{2}(\theta+\sin \theta \cos \theta)\right|_{x=a} ^{x=A} \\
& =\left.A^{2}\left(\sin ^{-1} \frac{x}{A}+\frac{x \sqrt{A^{2}-x^{2}}}{A^{2}}\right)\right|_{a} ^{A} \\
& =\frac{\pi}{2} A^{2}-A^{2} \operatorname{Sin}^{-1} \frac{a}{A}-a \sqrt{A^{2}-a^{2}}
\end{aligned}
$$

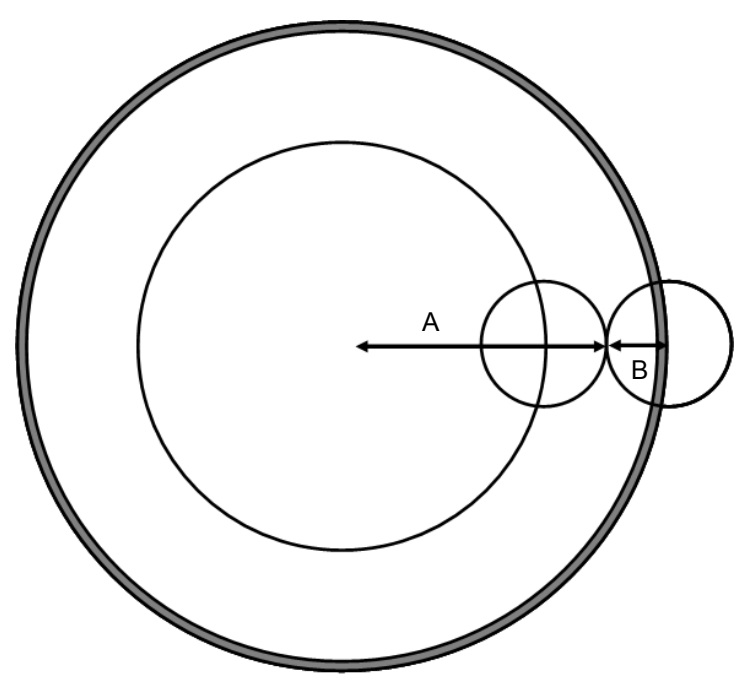

Figure 2. The chance of getting 100\% composition. 
Finally,

$$
\begin{aligned}
\operatorname{Area}(S)= & \operatorname{Area}\left(S_{a}\right)+\operatorname{Area}\left(S_{b}\right) \\
= & \left(\frac{\pi}{2} A^{2}-A^{2} \operatorname{Sin}^{-1} \frac{a}{A}-a \sqrt{A^{2}-a^{2}}\right)+ \\
& \left(\frac{\pi}{2} B^{2}-B^{2} \operatorname{Sin}^{-1} \frac{b}{B}-b \sqrt{B^{2}-b^{2}}\right)
\end{aligned}
$$

Given these equations, the probability of getting "pure (liberation)" size in sampling, that is, \% purity, is proposed (see Figure 2). $\%$ purity is obtained by integrating the multiplication of 'composition (\%) of pure A particle in sampled particle' and 'the differential area (which is obtained by changing the radius, $\mathrm{R}$, from $\mathrm{R}=\mathrm{a}+\mathrm{b}$ to $\mathrm{R}=0$ )', then dividing the result by the total area of the circle $(A+B)$. The chance of $100 \%$ composition is obtained when $\mathrm{R}<\mathrm{A}-\mathrm{B}$.

$$
\begin{aligned}
\% \text { purity } & =\frac{\text { composition }(\%) \times \text { differential area }}{\text { total area }} \\
& =\frac{\int_{0}^{A+B}\left(\left(\frac{100 \times \text { Area }(S)}{\pi B^{2}}\right) \times 2 \pi R\right) d R}{\pi \times(A+B)^{2}}
\end{aligned}
$$

A graph to predict the probability of the liberation size is shown in Figure 3. The ratio of $\mathrm{A} / \mathrm{B}$ implies the ratio of the particle radius of uniform density to the radius of the sampled small particle. In addition, if we change the $\mathrm{x}$ axis to the sampled particle size $(\mu \mathrm{m})$ on the basis of the mean osteon diameter of $150 \mu \mathrm{m}$ (i.e., a radius of $75 \mu \mathrm{m}),{ }^{16}$ we can obtain the probability of obtaining the liberation size in the $\mu \mathrm{m}$ scale (see Figure 4).

Histological Measurements. Histological measurements were carried out to assess the bone preservation state. Bone specimens were shot blasted using fine aluminum oxide $\left(\mathrm{Al}_{2} \mathrm{O}_{3}\right)$ powder to remove any surface contaminants that had adhered to the bone (Swam-Blaster $^{\mathrm{TM}}$, Crystal Mark, Inc., Glendale CA 91201; Airbrasive Powder no. 1, REG Abrasonics, Ltd., Dartford, Kent DA2 6H4, UK). They were then mounted with cold epoxy resin (Specifix epoxy resin: Specfix-20 hardener, 7:1 (w/w)) in a vacuum chamber and left to harden for 24 hours. Then, samples were ground using SiC paper on Grinder-Polisher (Buehler, Ltd., Coventry, UK) and polished with polishing texmet cloth and diamond paste, $(9 \mu \mathrm{m} \rightarrow 3 \mu \mathrm{m} \rightarrow 1 \mu \mathrm{m} \rightarrow 1 / 4 \mu \mathrm{m})$ (Metadi ${ }^{\mathrm{R}} \mathrm{II}$ diamond polishing compound, Buehler, Ltd., Coventry, UK) using Grinder-Polisher.

Finally, the bone histology was observed under optical microscopy under reflected light (Nikon, Japan). The preservation state of each sample was assessed and the extent of diagenetic alteration was assessed based on several qualitative aspects (see Table 1). This was scored from 0 to 5 .

Grinding Methods and Particle Size Analysis. Three different mills were used in this study, a Spex Freezer Mill (Spex 6700 $\mathrm{LN}_{2}$ Freezer/Mill, USA), a Disc Mill (TEMA, Machinery, Ltd. Banbury, Oxon, Laboratory Disc mill, UK), and a Micronising mill (McCRONE Micronising mill, McCrone Research Associates Ltd., USA). The Disc Mill and Micronising Mill were utilized at the School of Human and Environmental Sciences, University of Reading, in the UK. After grinding, the particle size distribution was measured by a Coulter Laser Particle Size Analyser (Beckham Coulter LS 230 laser granulometer, Roissy CDG,

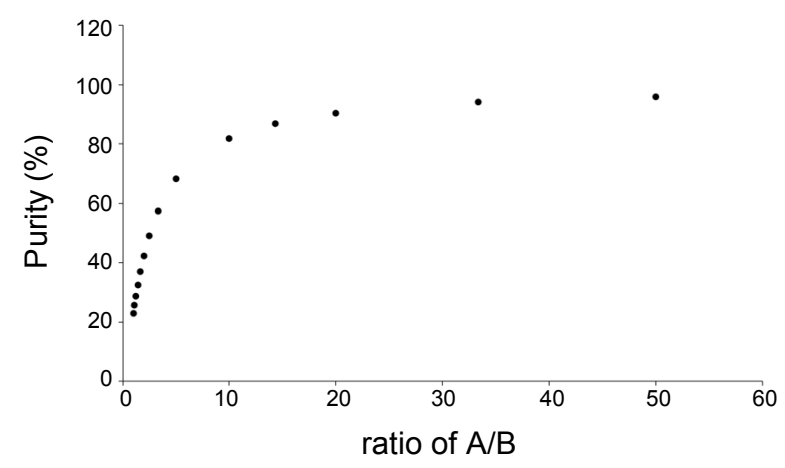

Figure 3. The probability of getting liberation size.

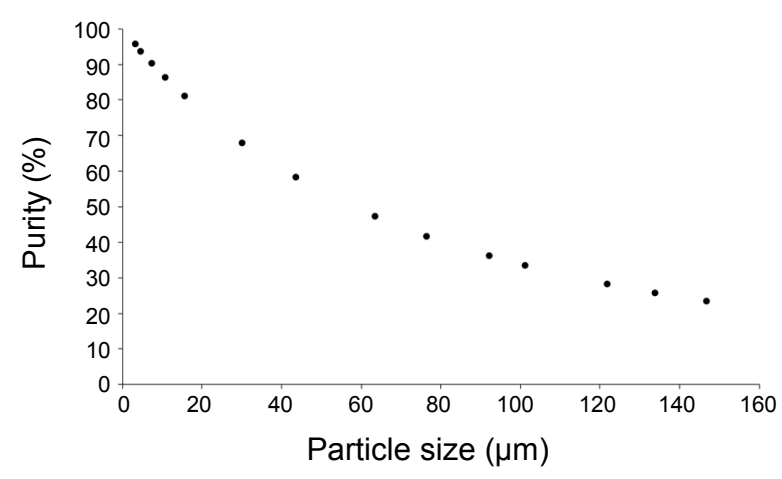

Figure 4. The probability of getting liberation size in $\mu \mathrm{m}$ scale.

Table 1. Histological index of bone $\mathrm{e}^{16,17}$

\begin{tabular}{ccc}
$\begin{array}{c}\text { HI histological } \\
\text { Index }\end{array}$ & $\begin{array}{c}\text { Approximate } \% \\
\text { of intact bone }\end{array}$ & Description \\
\hline 0 & $<5$ & No original features identifiable, except that Haversian canals may be present \\
1 & $<15$ & Haversian canals present, small areas of well-preserved bone present, or lamellate structure is \\
preserved by the pattern of destructive foci
\end{tabular}


France) within the range of $0.04-2000 \mu \mathrm{m}$. The measurements were confirmed by optical microscopy.

Bone Density Fractionation. The bone density fractionation method using organic solvent mixtures were applied after grinding and obtaining a suitable particle size distribution. ${ }^{9}$ Organic solvent mixtures of bromoform $\left(\mathrm{CHBr}_{3}, 2.89 \mathrm{~g} / \mathrm{cm}^{3}\right)$ and methanol $\left(\mathrm{CH}_{3} \mathrm{OH}, 0.79 \mathrm{~g} / \mathrm{cm}^{3}\right)$ were prepared using a calibrated hydrometer (Sometu, Falkenried 4, 14195, Berlin, Germany). Density fractions were then collected by centrifugation after differential flotation in a sequence of increasing density mixtures of bromoform and methanol $(8-10 \mathrm{~mL}$ was added to the centrifuge tube). Density fractions are expressed in the form of $\leq 1.8$, indicating the following: $\leq 1.8$ (lighter than $1.8 \mathrm{~g} / \mathrm{cm}^{3}, \leq 2.0(1.8 \sim$ $2.0), \leq 2.1(2.0 \sim 2.1), \leq 2.2(2.1 \sim 2.2), \leq 2.4(2.2 \sim 2.4), \leq 2.6$ $(2.4 \sim 2.6),>2.6$ (heavier than $2.6 \mathrm{~g} / \mathrm{cm}^{3}$ ). It is important to note that the normal density distribution for modern human bone ranges from 1.7 to $2.4 \mathrm{~g} / \mathrm{cm}^{3}$, depending on the age, growth, sex, nutrition and health status of the individual; the diagenetically altered density fraction lies beyond this range. ${ }^{17}$ Finally, each fraction was washed with methanol and distilled water three times in succession and then recentrifuged and freezedried under a vacuum for 48 hours.

Collagen Extraction and Stable Isotope Analysis. Each density-fractionated bone was washed in methanol, and distilled water. Bone collagen was extracted by demineralization in $0.5 \mathrm{M}$ aqueous $\mathrm{HCl}$, with gelatinization of the insoluble material at pH 3 for 48 hours at $75^{\circ} \mathrm{C}$ and subsequent lyophilization of the filtrate, using standard procedures. ${ }^{18}$ A $3-\mathrm{mg}$ aliquot of the product was then combusted in a continuous-flow isotope ratio mass spectrometer (Carlo Erba carbon and nitrogen elemental analyzer coupled to a Europa Geo 20/20 mass spectrometer, Sercon Ltd, Cheshire, UK) with $\mathrm{CO}_{2}, \mathrm{H}_{2} \mathrm{O}$ and $\mathrm{N}_{2}$ and measured for $\mathrm{C} / \mathrm{N}, \delta^{13} \mathrm{C}$ and $\delta^{15} \mathrm{~N}$. Typical replicate measurement errors are of the order of $\pm 0.2 \%$ for $\delta^{13} \mathrm{C}$ and $\delta^{15} \mathrm{~N}$.

\section{Results and Discussion}

Histological Measurements. Table 1 demonstrates the 'Histological index', where 5 implies very well preserved bone and 0 indicates poorly preserved bone with scarcely any original features. ${ }^{19,20}$ As noted above, changes in bone density attributed to microbial attack are closely related to histological morpho$\operatorname{logy}^{21,22}$

On the basis of Table 1, the histology of bone from Greyfriars (Figure 5) shows a better preservation state (index $3 \sim 4$ ) than that of Repton (Figure 6), which lies within the range of 0 to 1. In Figure 4, lamellate structures are revealed, while some osteocyte lacunae is preserved with minor amount of destructive foci. On the other hand, histological integrity is almost destroyed and re-allocated by 'tunnelling' and Haversian canals and small areas of lamellate structure is preserved by the pattern of destructive foci in Figure 5.

Particle Size Analysis. In Figure 7, the cumulative particle size distribution (\% volume) was drawn with \% purity curve (Figure 4). On the basis of the devised mathematical model, the particle size of $7.7 \mu \mathrm{m}$ shows $90.0 \%$ purity (see Figure 7 ). We can compare the particle size range using different grinding methods. Using Disc mill and Micronising mill together, 90.1\% (volume $\%$ ) of particles are within the range of $7.7 \mu \mathrm{m}(90.0 \%$ purity), whereas $50.9 \%$ (volume \%) using Disc mill, and $4.5 \%$ (volume \%) using Spex mill.

Density Distribution. It is worthwhile to review the pattern of the density distributions from the two sites. As noted above, normal density distribution in living bone ranges from 1.7 to $2.4 \mathrm{~g} / \mathrm{cm}^{3}$, therefore, we assume that the diagenetically altered density fraction lies beyond this range. The density profile from each site corresponds well with the histological index score, where the samples from the Repton site (RT1, RT2, RT3) present a relatively large proportion of the heavier density fractions, which lies beyond $2.4 \mathrm{~g} / \mathrm{cm}^{3}$, in comparison with that from the

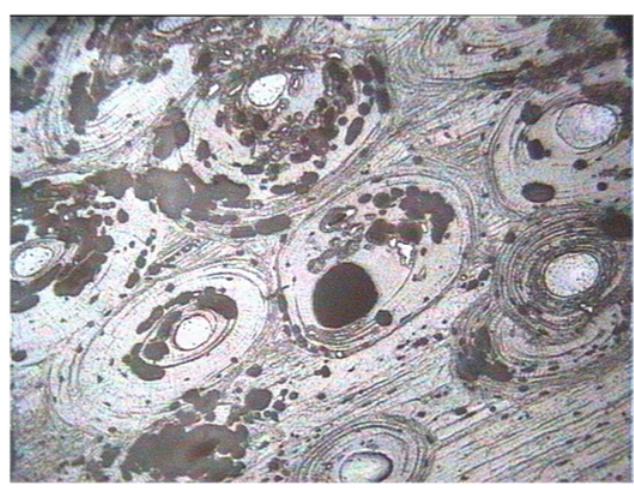

Figure 5. Micrograph of GF3 $(\times 10)$.

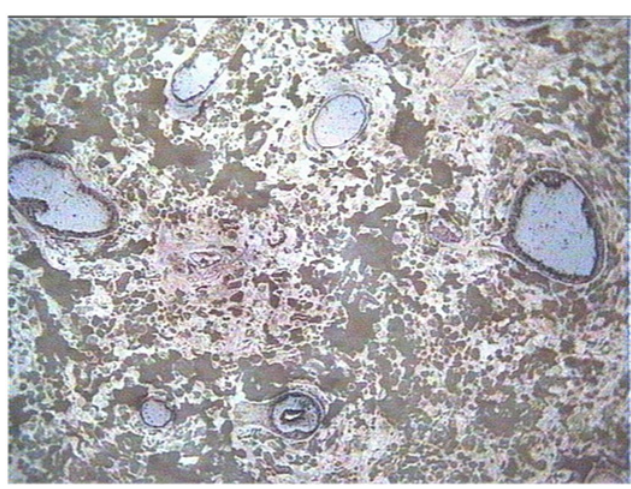

Figure 6. Micrograph of RT1 $(\times 10)$.

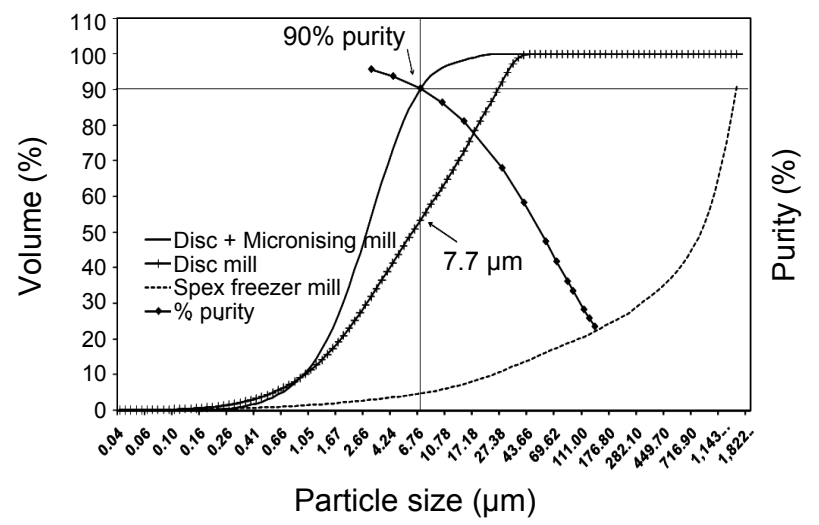

Figure 7. Comparison of liberation size with cumulative size distribution 


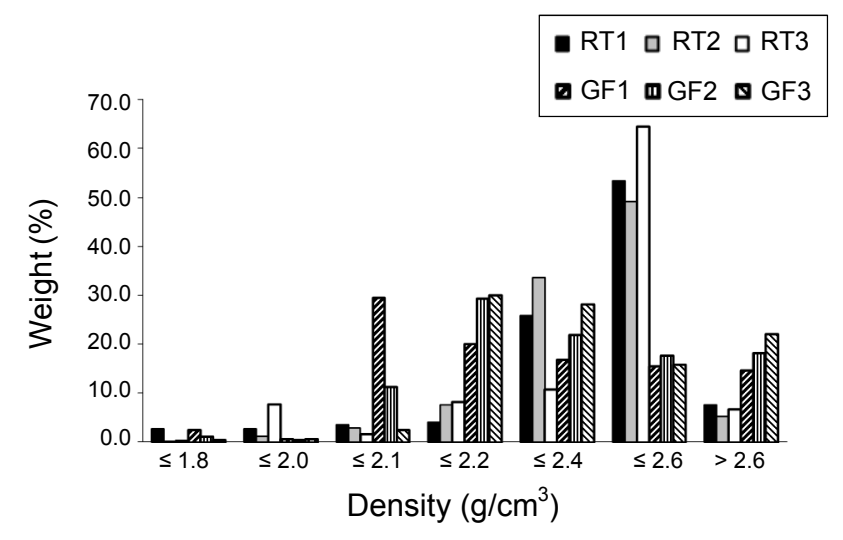

Figure 8. Density distribution histogram for the Greyfriars and Repton sites.

Table 2. Stable isotope results

\begin{tabular}{|c|c|c|c|c|}
\hline sample ID & $\delta^{13} \mathrm{C}(\%)$ & $\delta^{15} \mathrm{~N}(\%)$ & $\mathrm{C} / \mathrm{N}$ ratio & Collagen yield $(\%)$ \\
\hline $\mathrm{GF} 1 \leq 2.1$ & -18.2 & 12.6 & 3.3 & 13.6 \\
\hline $\mathrm{GF} 1 \leq 2.2$ & -18.3 & 12.4 & 3.3 & 12.3 \\
\hline $\mathrm{GF} 1 \leq 2.4$ & -18.4 & 12.6 & 3.3 & 8.4 \\
\hline $\mathrm{GF} 1 \leq 2.6$ & -18.8 & 12.6 & 3.4 & 2.6 \\
\hline GF1-bulk & -18.3 & 12.6 & 3.3 & 12.2 \\
\hline $\mathrm{GF} 2 \leq 2.1$ & -20.0 & 13.0 & 3.3 & 16.1 \\
\hline GF $2 \leq 2.2$ & -18.9 & 12.6 & 3.3 & 10.4 \\
\hline GF2 $\leq 2.4$ & -18.9 & 12.8 & 3.3 & 7.7 \\
\hline GF2-bulk & -18.9 & 12.7 & 3.3 & 11.1 \\
\hline $\mathrm{GF} 3 \leq 2.1$ & -19.8 & 10.7 & 3.3 & 7.2 \\
\hline $\mathrm{GF} 3 \leq 2.2$ & -19.7 & 10.4 & 3.3 & 11.7 \\
\hline $\mathrm{GF} 3 \leq 2.4$ & -19.5 & 10.6 & 3.3 & 7.8 \\
\hline $\mathrm{GF} 3 \leq 2.6$ & -19.8 & 11.0 & 3.4 & 3.9 \\
\hline GF3-bulk & -19.6 & 10.5 & 3.3 & 12.2 \\
\hline $\mathrm{RT} 1 \leq 2.4$ & -19.4 & 11.3 & 3.4 & 3.2 \\
\hline $\mathrm{RT} 1 \leq 2.6$ & -19.9 & 10.8 & 3.4 & 6.0 \\
\hline RT1-bulk & -19.4 & 10.9 & 3.3 & 7.1 \\
\hline $\mathrm{RT} 2 \leq 2.2$ & -19.9 & 11.0 & 3.4 & 5.1 \\
\hline $\mathrm{RT} 2 \leq 2.4$ & -20.5 & 11.1 & 3.6 & 1.6 \\
\hline $\mathrm{RT} 2 \leq 2.6$ & -20.4 & 10.9 & 3.6 & 1.3 \\
\hline RT2-bulk & -19.8 & 11.1 & 3.3 & 7.5 \\
\hline $\mathrm{RT} 3 \leq 2.2$ & -20.2 & 11.4 & 3.5 & 2.6 \\
\hline $\mathrm{RT} 3 \leq 2.4$ & -19.8 & 11.1 & 3.4 & 5.7 \\
\hline
\end{tabular}

※ Duplicate measurement, Typical replicate measurement errors are of the order of $\pm 0.2 \%$ for $\delta^{13} \mathrm{C}$ and $\delta^{15} \mathrm{~N}$.

Greyfrairs site (GF1, GF2, GF3), which shows better preservation state based on histological index (see Figure 8).

Stable Carbon and Nitrogen Isotope Results. The stable carbon and nitrogen results of the bulk bone collagen and its density fraction from two sites imply two main achievements (see Table 2). First, these measurements show very good internal agreement, also agreeing with the bulk measurement, presenting valid delta values $\left(\delta^{13} \mathrm{C}, \delta^{15} \mathrm{~N}\right)$ as assessed by various collagen quality indicators such as the collagen yield $(1-20 \%)$ and $\mathrm{C} / \mathrm{N}$ ratio $(2.9$ - 3.5). One of the reasons for the acceptance of bone collagen as a reliable palaeodietary tool is the existence of a

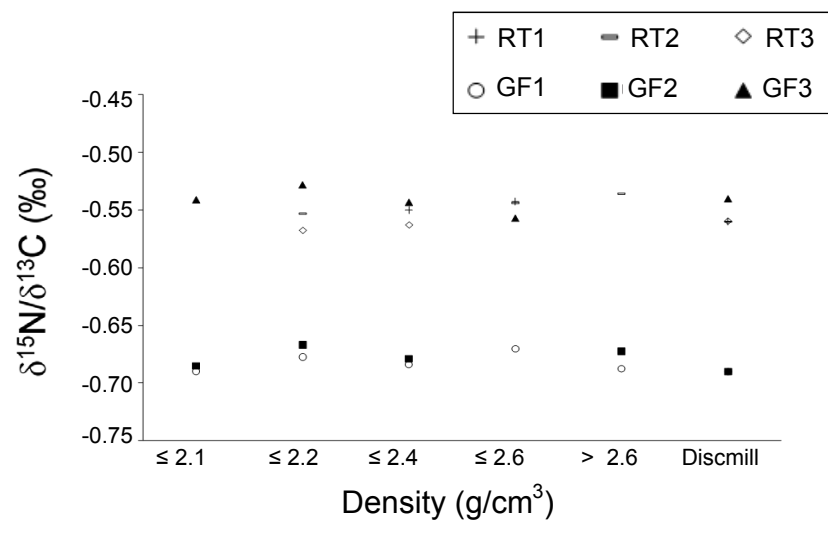

Figure 9. Plot of density $v s \delta^{15} \mathrm{~N} / \delta^{13} \mathrm{C}$ for the Greyfriars and Repton sites.

validity testing method, such as quality indicator. There are chemical and elemental indicators for checking a bone collagen quality indicator to ensure that the data is reliable. These indicators are highly relevant to the extent of diagenetic degradation, contamination and the type of extraction method employed. "Collagen" yield (weight percentage) is one of the chemical indicators, where "collagen" content is reported to decrease during burial where the speed relies on climatic conditions. It is found that the "collagen" content in temperate-to-subtropical climatic areas drops relatively slowly, while the temperature in arid to tropical zones drops more quickly. When the "collagen" content drops below $0.5 \%$, contamination becomes difficult to eliminate. Generally, collagen content is about $20 \%$ for modern bones, while $1-20 \%$ is normally accepted for archaeological bones. The C:N ratio is one of the most powerful "collagen" quality indicators. This ratio is derived from the $\mathrm{C}$ and $\mathrm{N}$ content of the extracted "collagen", ranged from 2.9 to 3.5 (3.2 modern). It is likely that high values $(>4)$ indicate extensive diagenesis or a high proportion of exogenous carbon (e.g. humics), whereas extreme values are more often found in low-"collagen" samples than in contaminated samples. ${ }^{18}$

Secondly, a relationship between the density fraction and collagen yield can be observed, where the density fraction from the biogenic part (lighter fraction) reflects a higher collagen yield than those from the diagenetic part (heavier fraction); samples with good histology (from Greyfriars) show an average collagen yield that is $4.23 \%$ higher than those with relatively poor histology (from Repton). It is worth noting that I used the same technical sample set used in a previous study, ${ }^{11}$ although here I provide different models and approaches.

Figure 9 shows that the $\delta^{15} \mathrm{~N} / \delta^{13} \mathrm{C}$ values for each density fraction agree quite well with a bulk measurement within $0.2 \%$. Stable isotope result of each density fraction (biogenic fraction and diagenetically altered fraction) as well as bulk fraction is within the replicate measurement error range $\left( \pm 0.2 \%\right.$ for $\delta^{13} \mathrm{C}$ and $\delta^{15} \mathrm{~N}$ ), which implies the retained isotopic integrity. Using stable isotope analysis $\left(\delta^{13} \mathrm{C}\right.$ and $\left.\delta^{15} \mathrm{~N}\right)$, we could extract the dietary information (terrestrial foodwebs $\left(\mathrm{C}_{3}\right.$ vs $\mathrm{C}_{4}$ vs $\mathrm{CAM}$ photosynthesis), aquatic and marine foodwebs, trophic level enrichment, nitrogen-fixing $v s$ non nitrogen-fixing plant) as well as environmental information (climate, aridity/humidity, 
salinity, soil type) and physiological information such as breastfeeding/weaning, growth, starvation and water stress. However, there is no special meaning for $\delta^{15} \mathrm{~N} / \delta^{13} \mathrm{C}$ values, and these values are plotted to check the isotopic integrity as noted above. This provides the consistency in the bone density fractionation method as applied to bone collagen.

Although this is the first attempt, and despite the lack of an ideal set, there is likely no significant masking or misinterpretation of the in vivo signatures from the diagenetic parts when we compare isotopic bone collagen results from heavier and lighter density fractions. This good internal agreement and lack of significant differences in the isotopic resulting from the density fractions may add reliability to routine stable isotope analyses of bone collagen and to the density fractionation method itself.

\section{Conclusion}

This research has shown the development of a workable density fractionation method as applied to archaeological human bones from two sites, Greyfriars (mediaeval) and Repton (Anglosaxon) using solvent mixtures of bromoform and methanol, modified from Bell et al. ${ }^{9}$ Different grinding methods, including a combination of a Disc mill and a Micronising mill, were used to reduce archaeological bone particles to an appropriate size range, which was then analyzed by a Laser particle sizer, and also validated by devised mathematical model. Although this is a preliminary research, we have obtained a reasonable degree of corroboration. The study investigated the dependence of the density distribution pattern on the preservation state. The density profiles from the two sites correspond well with the histological index score. In addition, the $\delta^{15} \mathrm{~N} / \delta^{13} \mathrm{C}$ values for each density fraction agree quite well with the bulk measurement, which adds to the consistency of this method. The isotope results of each density fraction and from the bulk collagen show similar values; this may provide through the selection of the least diagenetically altered fraction.
Acknowledgments. This work was supported by the Korea Research Foundation Grant funded by the Korean Government (KRF-354-2008-1-A00224).

\section{References}

1. Ambrose, S. H.; Norr, L. In Prehistoric Human Bone-Archaeology at the Molecular Level; Lambert, J. B., Grupe, G., Eds.; SpringerVerlag: Berlin, Germany, 1993; p 1.

2. Gannes, L. Z.; Rio, C. M.; Koch, P. Comp. Biochem. Physiol. 1998, $119 A, 725$

3. Vogel, J. C.; van der Merwe, N. J. Amer. Ant. 1977, 2, 238.

4. Ambrose, S. H.; Buikstra, J.; Krueger, H. W. J. Anth. Arch. 2003, 22,217

5. Pate, F. D.; Hutton, J. T.; Norrish, K. Appl. Geochem. 1989, 4, 303.

6. Hedges, R. E. M. Archaeometry 2002, 44, 319.

7. Nielsen-Marsh, C. M.; Smith, C. I., Jans, M. M. E.; Nord, A.; Kars, H.; Collins, M. J. J. Archaeol. Sci. 2007, 34, 1523.

8. Herman, H.; Richelle, L. Bull. Soc. Chim. Biol. 1961, 43, 273.

9. Bell, L. S.; Cox, G.; Sealy, J. Am. J. Phys. Anthropol. 2001, 116, 66.

10. Lammens, J.; Aerssens, J.; Nijs, J.; Mokassa, L.; Dequeker, J.; Bouillon, R.; Fabry, G. J. Orthop. Res. 1997, 15, 391

11. Shin, J. Y.; O'Connell, T. C.; Black, S.; Hedges, R. E. M. Radiocarbon 2004, 46(2), 853 .

12. Lowenstam, H. A.; Weiner, S. On Biomineralization; Oxford University Press: 1989; Chap 9.

13. Jans, M. M. E.; Nielsen-Marsh, C. M.; Smith, C. I.; Collins, M. J.; Kars, H. J. Archaeol. Sci. 2004, 31, 87.

14. Smith, C. I.; Nielsen-Marsh, C. M.; Jans, M. M. E.; Collins, M. J. J. Archaeol. Sci. 2007, 34, 1485.

15. Richelle, L. J. Clin. Orthop. 1964, 33, 211.

16. Fincham, A. G. Calcif. Tissue Res. 1969, 3, 327.

17. Grynpas, M. Calcif. Tissue Int. 1993, 53, S57.

18. van Klinken, G. J.; Hedges, R. E. M. Radiocarbon 1998, 40, 51-56.

19. Hedges, R. E. M.; Millard, A. R.; Pike, A. W. G. J. Archaeol. Sci. 1995, 22, 201.

20. Millard, A. R. In Handbook of Archaeological Sciences; Brothwell, D. R., Pollard, A. M., Eds.; John Wiley \& Sons, Ltd.: p 637.

21. Hedges, R. E. M. Archaeometry 2002, 44, 319.

22. Turner-Walker, G.; Syversen, U. Archaeometry 2002, 44, 461. 